\title{
Additive manufacturing of $\mathrm{CuCr} 1 \mathrm{Zr}$ by development of a gas atomization and laser powder bed fusion routine
}

\author{
Katrin Jahns ${ }^{1,2} \cdot$ Robin Bappert ${ }^{1,2} \cdot$ Peter Böhlke ${ }^{2}$ Ulrich Krupp ${ }^{3}$
}

Received: 28 August 2019 / Accepted: 14 January 2020 / Published online: 16 March 2020

(C) The Author(s) 2020

\begin{abstract}
The research focuses on alloy design, powder production, and laser powder bed fusion (LPBF) of copper alloys. Copper and its alloys play a fundamental role for modern industrial applications due to their excellent thermal and electric conductivity in conjunction with considerable mechanical strength, for example, as welding electrodes and nozzles. By precipitation hardening, the hardness of low-alloyed copper, like CuCr1Zr, can be increased significantly. A combination of the geometry freedom of additive manufacturing with a tailor-made alloy design during powder production offers the opportunity to develop new alloy systems with a focus on the respective application. Experimental results regarding gas atomization, LPBF, property investigations, and property optimization of $\mathrm{CuCr} 1 \mathrm{Zr}$ are presented. Powder particles and LPBF parts were analyzed with respect to phase and precipitate formation and compared to benchmark experiments of conventionally cast copper alloys. The microstructure differs significantly. Furthermore, the relative density of the LPBF parts reaches a value of $99.8 \%$.
\end{abstract}

Keywords Laser powder bed fusion · Gas atomization · Copper alloys · Additive manufacturing ·

Precipitation strengthening

\section{Introduction}

Due to their outstanding thermal and electric conductivity [1] in combination with wide-range alloying abilities, copper and its alloys are highly significant in the development of new electronic and heat-exchanging units, e.g., in electro mobility and novel power generation and distribution units. The originally poor strength of $\mathrm{Cu}$ alloys can be increased by precipitation hardening, without losing the outstanding electric and thermal conductivity properties $[2,3]$. Examples are the systems $\mathrm{CuCrZr}$ and $\mathrm{CuNiSiCr}$, where $\mathrm{Cr}, \mathrm{Ni}_{2} \mathrm{Si}, \mathrm{Cu}_{4} \mathrm{Zr}$, and $\mathrm{Cr}_{2} \mathrm{Zr}$ strengthening phases are formed [2-5]. Within these alloys, Cr precipitates are

Katrin Jahns

k.jahns@hs-osnabrueck.de

1 Institute of Materials Design and Structural Integrity, University of Applied Sciences Osnabrück, Osnabrück, Germany

2 KME Germany GmbH, Co. KG, Osnabrück, Germany

3 Steel Institute, RWTH Aachen University, Aachen, Germany formed during casting due to the poor solubility of $\mathrm{Cr}$ in the Cu matrix (see Fig. 1).

An alternative to restrictive conventional production methods is given by additive manufacturing (AM). Generation of individually tailored 3D metallic parts has been established by laser beam or electron beam based powder bed processes. Furthermore, direct energy deposition (DED) as laser metal deposition (LMD) with metal powders or wires may be used for the generation of 3D structures (see [6-8]), repair of degraded components [9, 10] and application of functional graded alloy systems [11, 12]. For manufacturing of highly individual 3D components, the laser powder bed fusion (LPBF) may be applied where a laser beam is used to selectively melt metal powders. During LPBF, multilayer micro-welding processes are activated for generation of macroscopic structures, i.e., metal powder is transformed into bulk material of a grain size between 10 and $60 \mu \mathrm{m}$ by remelting 20 to $100 \mu \mathrm{m}$ layers on a substrate plate. Furthermore, a large temperature gradient is occurring, originating from the repetitive rapid heat and solidification during the distinct micro-welding processes of each layer [13, 14]. This gradient influences significantly the microstructure of the LPBF-built parts and may result in defects like cracking [15] or part distortion [16]. 


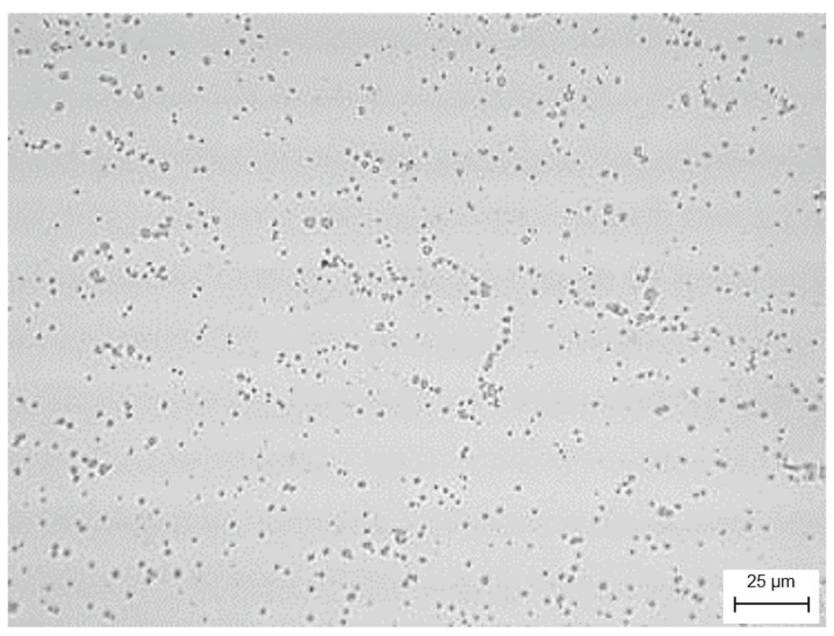

Fig. 1 Light microscopy images of $\mathrm{Cr}$ precipitate formation in cast $\mathrm{CuCr} 1 \mathrm{Zr}$, taken from own work

Furthermore, an understanding of the melt pool induced by the micro-welding processes and the melt pool dynamics (see $[17,18]$ ) allows the adjustment of the LPBF-built microstructures [19]. For the consideration of the melt pool and temperature fields during the LPBF process, analytical and numerical approaches are available (see for example $[14,20,21])$.

Besides the LPBF process itself, metallurgical processing of high-quality powders plays a crucial role within the additive manufacturing process chain in order to build dense and defect-free parts. Taking the recent literature state into account, it can be concluded that the quality of the applied powders in combination with the process parameters determine the success of additive manufacturing [22]. Impurities and gas inclusions being already present in the powder are incorporated during the melting process and lead to pores and imperfections. One possibility to produce LPBF powders with suitable particle size distributions in the range between $10 \mu \mathrm{m}$ and $100 \mu \mathrm{m}$ is gas atomization by application of the close-coupled method [23, 24].

When considering LPBF of $\mathrm{Cu}$ alloys with $\mathrm{Cu}$ concentrations exceeding $95 \%$, the complete and defect-free melting of the powder is associated with considerable difficulties [2]: (i) the laser beam reflection is very high (approximately 98\%) for wave lengths of about $1050 \mathrm{~nm}$ (infra-red), as it is commonly used for the LPBF process, and (ii) the high thermal conductivity of $\mathrm{Cu}$. A large beam reflection results in a low process efficiency, since the major amount of the laser power is reflected and not available for powder melting. The high thermal conductivity causes a rapid loss of the spot energy required for heating and melting of the surrounding material. Therefore, $\mathrm{LPBF}$ of $\mathrm{Cu}$ is associated with the risk of unstable process conditions with inadequate local energy supply, preventing the manufacturing of dense and defect-free components [3].
However, defects in LPBF-built parts lead to a deterioration of the mechanical properties. In [27], parameter studies on oxygen-free, high-conductivity (OFHC) copper with small amount of phosphor (0.03-0.6 wt.\%) were performed and samples reached relative densities of only $92 \%$ for laser sources of $300 \mathrm{~W}(1060 \mathrm{~nm})$. For $\mathrm{Cu}-\mathrm{Cr}-\mathrm{Zr}-\mathrm{Ti}$ alloys, a density of $97.9 \%$ was obtained [28], when using a laser source of $400 \mathrm{~W}$. However, the porosity led to a reduction of the ultimate tensile strength of 20 to $25 \%$ compared to hot-rolled samples, which might be caused by residual porosity in the LPBF material [28]. When increasing the laser source to a value of $2000 \mathrm{~W}$, relative densities of 99.98\% could be reached for $\mathrm{CuCr} 0.5$ [29]. Furthermore, the application of post-LPBF heating procedure led to a higher ultimate tensile strength and electrical conductivity compared with heat-treated samples after rolling [29]. Similar results were found in $\mathrm{Cu}-\mathrm{Cr}$ alloys with $\mathrm{Cr}$ contents by 20 wt. $\%$ and 25 wt.\% [30]. For a Cu7.2Ni1.8Si1Cr provided by Sandvik Osprey Ltd., a relative density of $99.9 \%$ without any cracks was achieved [31].

In the present study, an additive manufacturing processing routine for $\mathrm{CuCr} 1 \mathrm{Zr}$ has been developed by combination of gas atomization and LPBF. The powders as well as the LPBF-built specimen were analyzed metallographically and the functional properties (density, electrical conductivity) and hardness were investigated. The aim of the study is to satisfy the demand from industry to qualify the alloy $\mathrm{CuCr} 1 \mathrm{Zr}$ for additive manufacturing with reproducible material properties by development of a very specialized gas atomization-LPBF-post-treatment routine. $\mathrm{CuCr} 1 \mathrm{Zr}$ is of high technological relevance as it is a hardenable $\mathrm{Cu}$ alloys with a high electric conductivity that may be used, e.g., for electrodes, welding nozzles, or as current-carrying plugs. For these application, it is inevitable to have a welldefined material whose properties are reproducible. As LPBF of copper alloys is challenging, the main tasks of this study are (i) the derivation of a manufacturing routine, (ii) the identification and definition of process parameters for gas atomization and LPBF, and (iii) the characterization of material properties of the additively manufactured part compared to a cast benchmark sample.

\section{Experimental procedure}

\subsection{Gas atomization}

In order to generate powders suitable for LPBF, a gas atomizer Indutherm AU3000 was used. Figure 2a shows schematically the gas atomization process. The $\mathrm{Cu}$ alloy was pre-alloyed in a graphite crucible and inductively melted at $1450^{\circ} \mathrm{C}$. Afterwards, the melt was released via a nozzle into the inert-atmosphere atomization vessel. Here, the melt was 
Fig. 2 Powder production by gas atomization. a Close-coupled mode with formation of a low-pressure area underneath the nozzle. b Gas atomization process within an Indutherm AU3000 atomizer
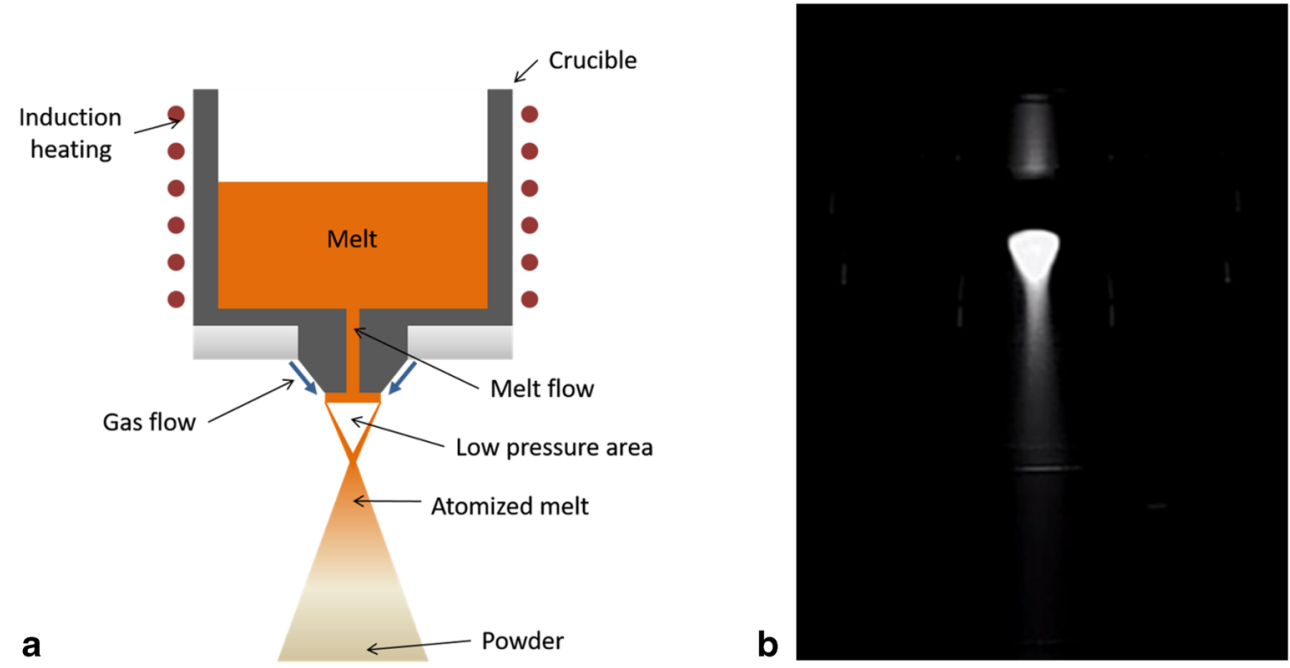

atomized by pressurized Ar (12 bar) at an Ar gas flow of $360 \mathrm{~m}^{3} / \mathrm{h}$. During the process, the close-coupled mode was used where the gas flow was regulated and fed in a way that a low-pressure was established underneath the nozzle (see blue arrows in Fig. 2a) resulting in the formation of particles sizes below $100 \mu \mathrm{m}$ [23, 24].

Figure $2 \mathrm{~b}$ shows the melt flow and the visible formation of the low-pressure area underneath the nozzle. Here, the melt solidifies with very high cooling rates up to $10^{6} \mathrm{~K} / \mathrm{s}$, leading to the formation of powder particles. After atomization and sieving using a $60 \mu \mathrm{m}$ sieve, the fine particle fractions $(d<10 \mu \mathrm{m})$ were removed by air separation. The powders were either used directly within the LPBF machine or stored in closed vessels.

The powders were analyzed metallographically regarding particle size, microstructure, precipitate formation, and the occurrence of porosity by application of high-resolution scanning electron microscopy (SEM Zeiss Auriga) in combination with energy-dispersive X-ray spectroscopy (EDX) and focused ion beam milling (FIB). Furthermore, the particle size distribution was obtained by (i) SEM and (ii) laser diffraction using a Malvern Mastersizer 2000 at RWTH Aachen University. The flowability was characterized by a Hall Flow Meter according to DIN EN ISO 4490 and the bulk density according to DIN EN ISO 3923-1.

As material, the alloy $\mathrm{CuCr} 1 \mathrm{Zr}$ was used which is applied in a wide range of application cases: as molds and cooling inserts for metal casting, electrodes, welding technology, current-carrying parts in electro-technology, or as parts for temperature control of plastic molds. $\mathrm{CuCr}$ was prealloyed in a graphite crucible of a separate casting furnace and further alloyed within the crucible of the atomizer. The chemical composition of the powders at every step of the process chain (before/after air separation and sieving, respectively) was analyzed and controlled by wet chemical analysis.

\subsection{Laser powder bed fusion}

Suitable powders were used for LPBF by using an EOS M290 machine which is equipped with a $400 \mathrm{~W}$ red laser system and powder bed monitoring. In order to define process parameters for LPBF, a parameter study was used where the laser power and the laser scanning velocity were systematically varied, using a linear hatching strategy with a hatching distance of $0.1 \mathrm{~mm}$. For every powder application, the direction of hatching was rotated by $67^{\circ}$. A layer thickness of $20 \mu \mathrm{m}$ was applied. As geometry, density cubes with $0.8 \times 0.8 \times 0.8 \mathrm{~cm}$ were used that were built on a support structure to allow an easy separation from the building plate. For each applied building strategy, three cubes were build under the same process conditions in order to account for possible uncertainties and variations within the building process. A round building plate made of the stainless steel $316 \mathrm{~L}$ with a diameter of $10 \mathrm{~cm}$ was used.

The cubic samples were cut, ground, and polished before the microstructue was analyzed by application of highresolution SEM in combination with EDX and electron backscatter diffraction (EBSD). Selected samples were etched or electrolytically polished with D2 electrolyte (containining phosphorid acid) by Struers. Furthermore, transmission electron microscopy (TEM, Zeiss Libra) was applied in order to characterize precipitates on the nano-scale. Beside the microstructural investigations, the functional properties of the specimen were analyzed depending on the process parameters for LPBF. These are (i) the relative density by usage of a Keyence digital microscope, (ii) the electrical conductivity, (iii) the surface roughness by application of both the profile method according to DIN EN ISO 4288 and a confocal Nanofocus system, and (iv) the hardness by using a Fischerscope microhardness testing device. The relative density was 
Table 1 Chemical composition (in wt.\%) of $\mathrm{CuCr} 1 \mathrm{Zr}$ samples at different states of production compared to the nominal chemical composition

\begin{tabular}{llll}
\hline CuCr1Zr state & $\mathrm{Cu}$ & $\mathrm{Cr}$ & $\mathrm{Zr}$ \\
\hline Standard (2.1293/CW106C) & bal. & $0.5-1.2$ & $0.03-0.30$ \\
Powder after gas atomization & bal. & 0.69 & 0.09 \\
Powder after gas atomization and air separation & bal. & 0.67 & 0.13 \\
Specimen after LPBF & bal. & 0.71 & 0.12 \\
\hline
\end{tabular}

measured according to VDI 34052 for five images on three cross sections per cubic sample. The electric conductivity and hardness were measured three times for all sides of the cubes on three individual cubes with the same building strategy. All respective values are averaged. For the sake of legibility, the error bars are omitted in the presentation of the results but mentioned within the discussion. Finally, a precipitation hardening routine was applied $\left(480^{\circ} \mathrm{C}\right.$ for $4 \mathrm{~h}$ ) in a tube furnace under vacuum in order to achieve an increase in hardness. The chemical compositions of the LPBF-built samples were analyzed by wet chemical analysis. As benchmark, reference samples of $\mathrm{CuCr} 1 \mathrm{Zr}$ were analyzed that had been cast and formed.

\section{Results and discussion}

\subsection{Microstructural investigation of gas-atomized powders}

At every step of the process chain, the chemical composition of the gas-atomized powders was analyzed by wet chemical analysis and compared with the nominal chemical composition of $\mathrm{CuCr} 1 \mathrm{Zr}$. Table 1 summarized the measured compositions. It becomes obvious that the chemical compositions of all analyzed samples lie within the nominal range of $\mathrm{CuCr} 1 \mathrm{Zr}$ according to the requirements for the alloy 2.1293/CW106C [3]. No considerable variations in the respective amount were detectable, which leads to the conclusion that the process was stable with respect to the alloy composition.

Figure 3 shows results of the investigations performed on the $\mathrm{CuCr} 1 \mathrm{Zr}$ powders. The SEM image of Fig. 3a reveals the occurrence of spherical powder particles and only occasional satellite formation. Furthermore, the particle size distribution in Fig. 3c, measured and analyzed by laser diffraction, reveals a distribution suitable for LPBF and a median diameter $d(0.5)$ of $42.05 \mu \mathrm{m}$ before and $42.12 \mu \mathrm{m}$ after air separation.
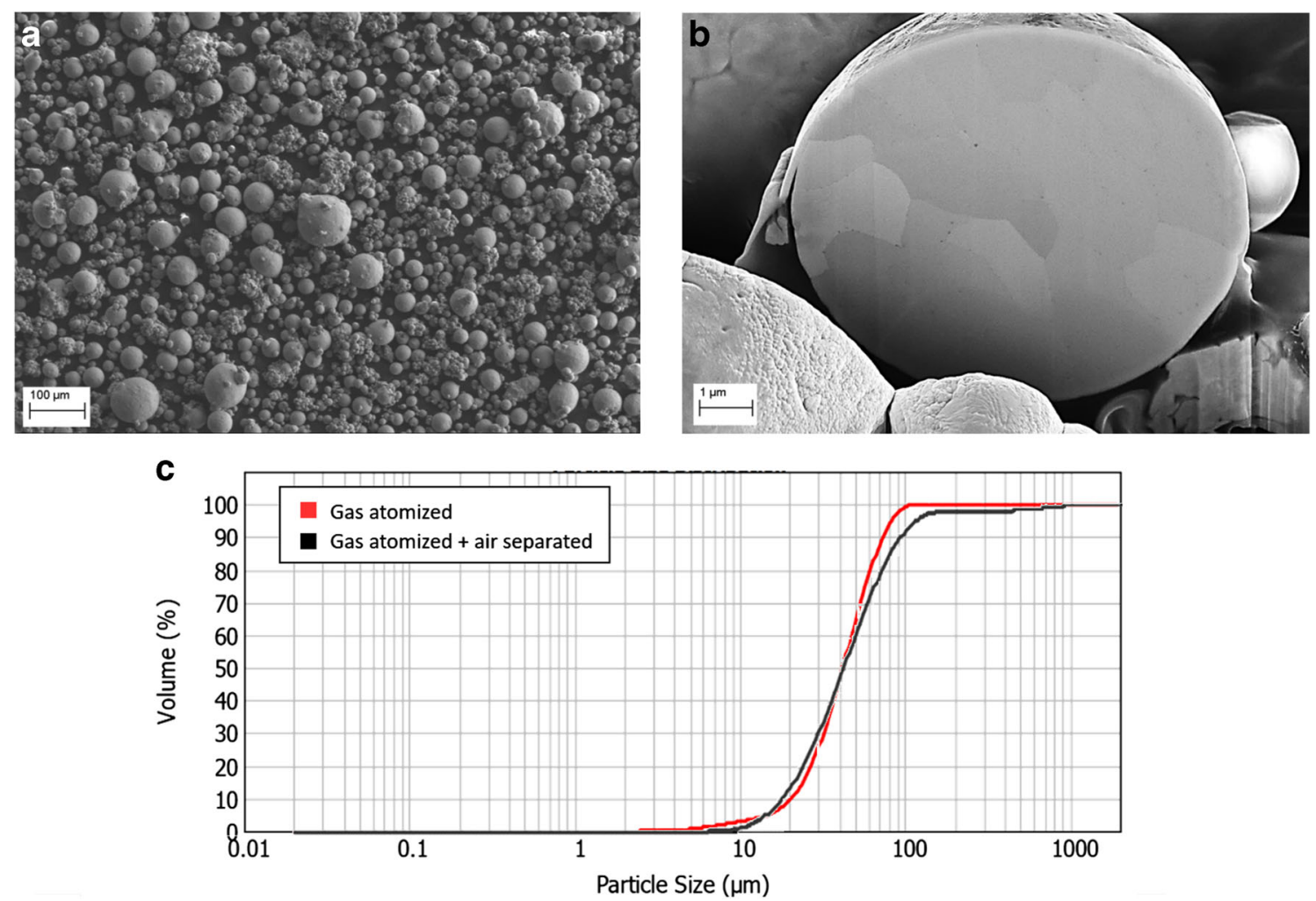

Fig. 3 Results for gas-atomized $\mathrm{CuCr} 1 \mathrm{Zr}$ powder particles. a SEM image of the particle distribution, $\mathbf{b}$ FIB image with visible grain structure and $\mathrm{ZrO}_{2}$ precipitate formation at the grain boundaries. $\mathbf{c}$ Particle size distribution before and after air separation to a revealing a suitable distribution for LPBF with a $d(0.5)$ of $42.05 \mu \mathrm{m}$ and $42.12 \mu \mathrm{m}$, respectively 
Fig. 4 Light microscopy images of two different LPBF parameter sets for $\mathrm{CuCr} 1 \mathrm{Zr}$. a $100 \mathrm{~W}$, $800 \mathrm{~mm} / \mathrm{s}$ with a density of $92.81 \% \pm 0.34 \%$. b $370 \mathrm{~W}$, $400 \mathrm{~mm} / \mathrm{a}$ with a density of $99.84 \% \pm 0.09 \%$ and remarkably lower pore formation
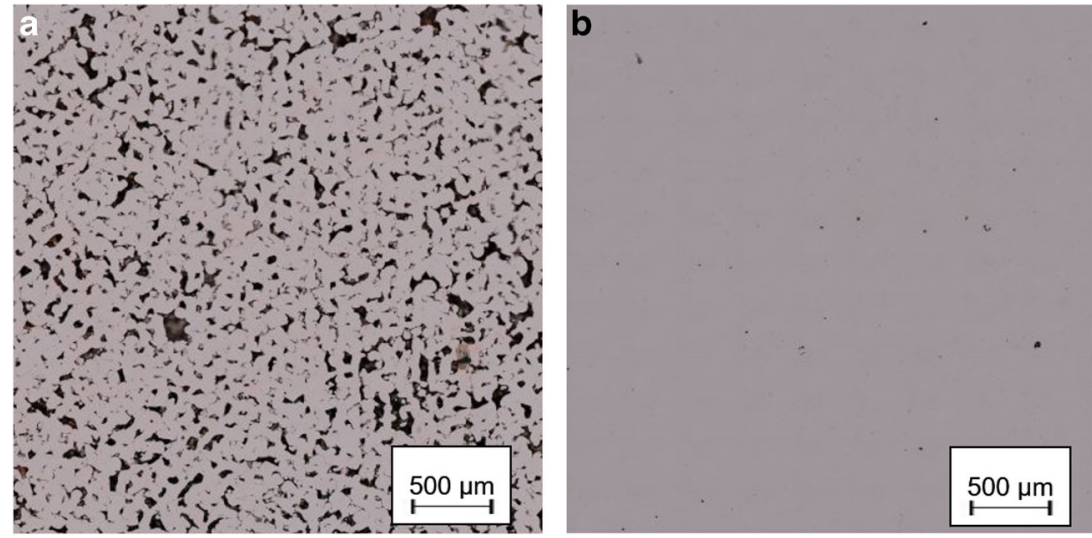

Comparing the two curves for the gas-atomized powders before and after air separation, respectively, shows that the finest particles with diameters lower than $10 \mu \mathrm{m}$ were successfully removed. The Hall Flow test on the airseparated powder according to DIN EN ISO 4490 in order to assess the flowability revealed a value of $14.4 \mathrm{~s}$ which is below the maximum value of $50 \mathrm{~s}$, and the bulk density test according to DIN EN ISO 3923-1 exhibits a value of 55\% which has to be between 50 and $60 \%$ in order to be suitable for LPBF. Both values are in the typical range for LPBF [25]. Altogether, the produced powder was assessed to be generally usable for LPBF.

Microstructural investigations were performed by FIBSEM after fixation of powder particles on a sample holder with nickel cement. Figure $3 b$ shows the resembling FIB cut through a powder particle. Within the particle, the grain structure is clearly visible with grain sizes between 6 and $10 \mu \mathrm{m}$. Compared to Fig. 1, no Cr precipitates are visible. Only at the grain boundaries, small occasional precipitates are visible which are identified by EDX as $\mathrm{ZrO}_{2}$. Due to the high cooling rates during gas atomization, the formation of $\mathrm{Cr}$ precipitates is restrained and $\mathrm{Cr}$ remains dissolved within the $\mathrm{Cu}$ matrix. Thus, the hypothesis is emphasized that the formation of $\mathrm{Cr}$ precipitates might also be suppressed after LPBF and that the alloying elements are then in solid solution.

\subsection{Investigation of LPBF-built samples}

For LPBF, the gas-atomized, air-separated, and sieved powders were used within a parameter study in order to identify the process parameters for $\mathrm{CuCr} 1 \mathrm{Zr}$. Therefore, the laser power was varied between 50 and $370 \mathrm{~W}$. Further, three different laser scanning velocities $(400 \mathrm{~mm} / \mathrm{s}$, $600 \mathrm{~mm} / \mathrm{s}$, and $800 \mathrm{~mm} / \mathrm{s}$ ) were applied. In a first step, light microscopy investigations and the determination of the relative density as well as the electric conductivity were performed for all samples of the parameter study.
Furthermore, the microstructure and surface roughness was investigated by means of SEM for selected samples.

Relative density The relative density was obtained optically by measuring the relationship between the analysis and pore area for five areas on a sample and subsequent averaging of the respective values. Figure 4 shows light microscopy images for two different parameter sets and a clearly visible difference with respect to pore formation. In Fig. 4a, a laser power of $100 \mathrm{~W}$ and a laser scanning velocity of $800 \mathrm{~mm} / \mathrm{s}$ were used. These parameters lead to a distinct pore formation within the LPBF-built sample with a relative density of $92.81 \% \pm 0.34 \%$. Increasing the laser power to a value of $370 \mathrm{~W}$ and concurrent decelerating the laser scanning velocity to $400 \mathrm{~mm} / \mathrm{s}$ (see Fig. 4b) resulted in a relative density of $99.84 \% \pm 0.09 \%$, which becomes also obvious when regarding the lower pore formation as compared to Fig. 4a.

In Fig. 5, the relative density is shown for all parameter sets of the parameter study. The values presented in Fig. 5 were obtained according to VDI 34052 and averaged.

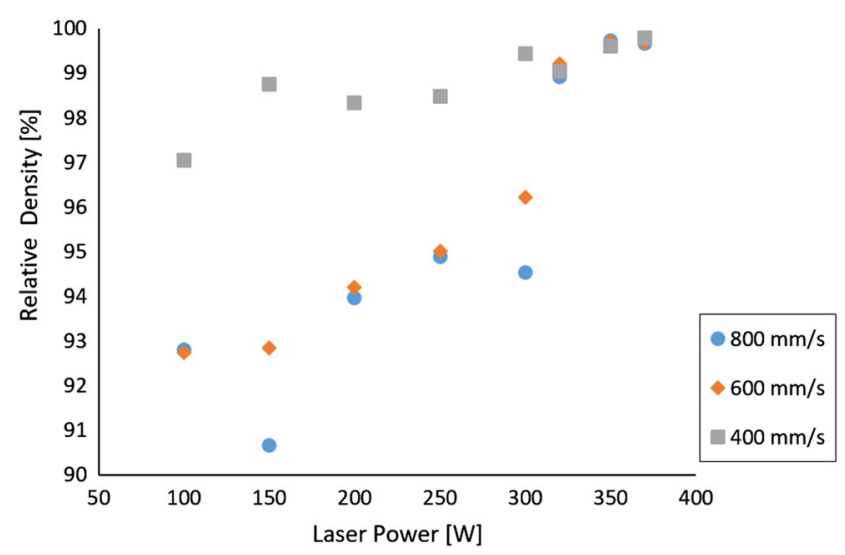

Fig. 5 Relative density of $\mathrm{CuCr} 1 \mathrm{Zr}$ as measured within the parameter study 
The best values with densities above $98 \%$ were achieved when either a laser scanning velocity of $400 \mathrm{~mm} / \mathrm{s}$ or a laser power of $370 \mathrm{~W}$ was used. However, the samples with densities above $99.5 \%$ were only achieved with laser powers exceeding $300 \mathrm{~W}$ for a laser scanning velocity of $400 \mathrm{~mm} / \mathrm{s}$. With a density of $99.84 \% \pm 0.09 \%$, the best value was achieved for $370 \mathrm{~W}$ for all laser scanning velocities. Faster laser scanning velocities led to unstable microwelding conditions and, therefore, pore formation. Only when applying a laser power of $370 \mathrm{~W}$, a relative density of $99.75 \% \pm 0.12 \%$ was achieved for a laser scanning velocities of $600 \mathrm{~mm} / \mathrm{s}$ and $800 \mathrm{~mm} / \mathrm{s}$. When applying a laser power of $50 \mathrm{~W}$, no metallic joint between the sample and the building plate was achieved and the jobs were aborted. Altogether, in order to further quantify the material properties of LPBFbuilt $\mathrm{CuCr} 1 \mathrm{Zr}$, only laser powers above $300 \mathrm{~W}$ and a laser scanning velocity of $400 \mathrm{~mm} / \mathrm{s}$ are recommendable and will be used for ongoing studies.

Microstructural investigations On samples with the parameter set at $370 \mathrm{~W}$ and $400 \mathrm{~mm} / \mathrm{s}$, as identified before to result in the most dense samples, microstructural investigations by application of high-resolution SEM were performed. Figure 6 shows SEM images of backscattered electrons (BSE) of microstructures perpendicular and parallel to the building direction, respectively. Regarding Fig. 6, it becomes obvious that neither $\mathrm{Cr}$ nor alternate precipitates formed were present in the cast state. EDS investigations confirm that the alloy elements $\mathrm{Cu}$ and $\mathrm{Cr}$ are in solid solution and equally distributed over the whole sample. Within the BSE micrographs, the grain structure perpendicular and parallel to the building direction is visible. Figure $6 \mathrm{~b}$ reveals that elongated grains were formed in building direction with lengths exceeding $10 \mu \mathrm{m}$. A deviation of the elongated grains compared to the building direction of about $40^{\circ}$ is visible within the BSE image of Fig. 6b. Perpendicular to the building direction, the grains are smaller and equiaxed (see Fig. 6a).

For further investigation of the microstructure, EBSD analyses were performed; the result of which is shown by the crystal-orientation mapping (IPF) in Fig. 6c, revealing the formation of elongated grains along the building direction (see Fig. 6c) in conjunction with Fig. 6b. The $<100>$ pole figure of Fig. $6 d$, which is based on the orientation data achieved from the EBSD measurement, shows a deviation from the $\mathrm{z} 0$ building direction (accumulation within the polfigure, red area) at approx. $40^{\circ}$ and a resulting tilt in $\mathrm{x} 0$ and $\mathrm{y} 0$ direction. This

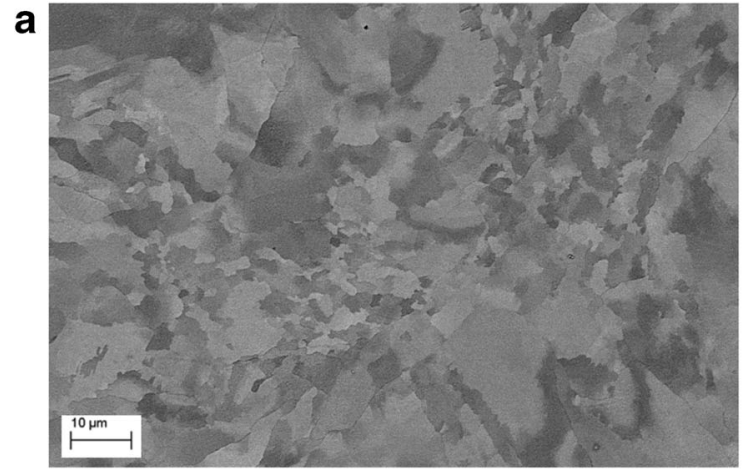

C

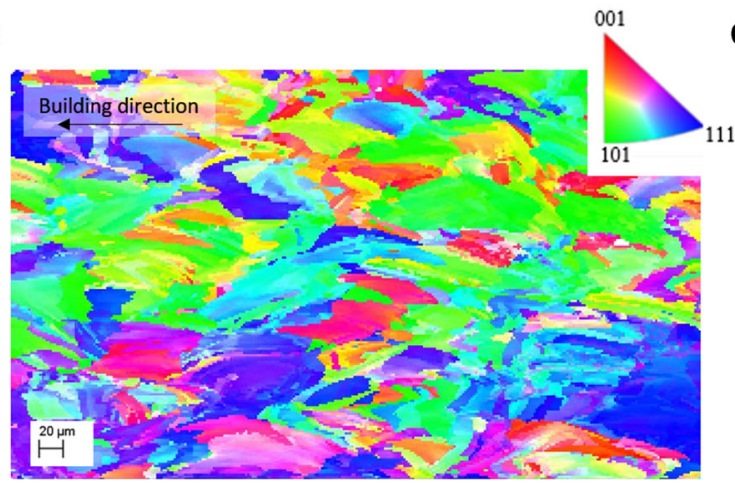

Fig. 6 BSE micrographs of $\mathrm{CuCr} 1 \mathrm{Zr}$ built by LPBF showing a the microstructure perpendicular to the building direction and $\mathbf{b}$ the microstructure parallel to the building direction. c EBSD image of

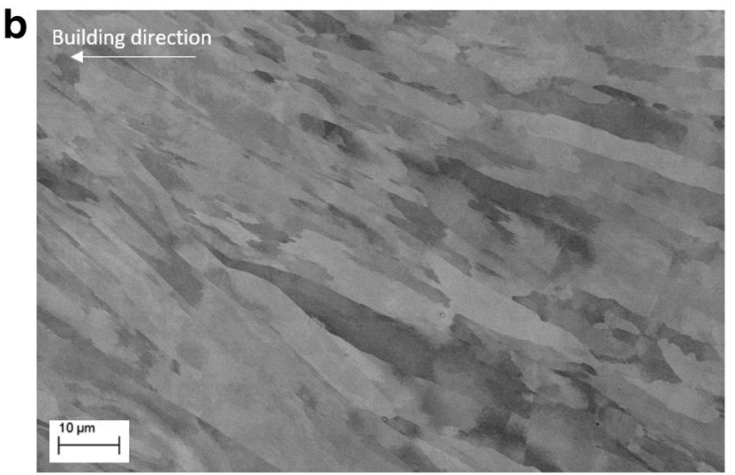

d

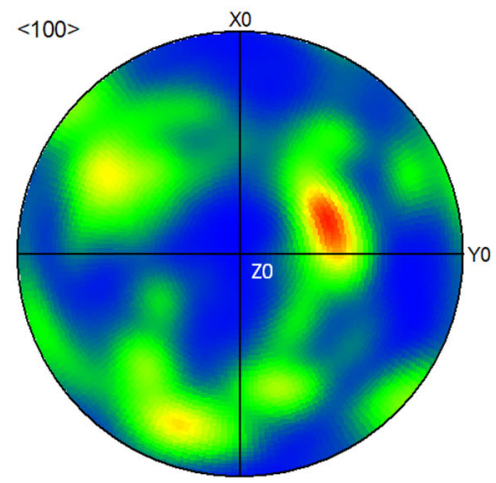

CuCr1Zr: crystal-orientation mapping (IPF) and $\mathbf{d}<100>$ pole figure according to the orientation data of a (red: high amount, blue: low amount) 


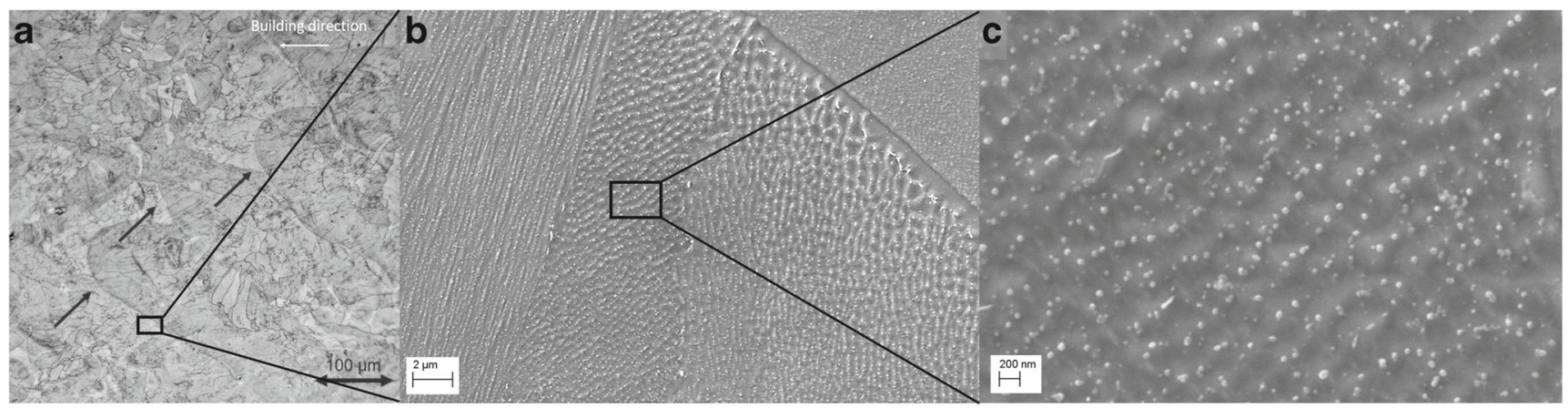

Fig. 7 SEM image of $\mathrm{CuCr} 1 \mathrm{Zr}$ built by LPBF. a Grain structure and melting lines (arrows) (cross section, polished and etched). b Formation of a cellular solidification structure oriented parallel and perpendicular to the image plane (cross section, electrolytically polished). c Formation of (probably) $\mathrm{ZrO}_{2}$ on the nano-scale (cross section, electrolytically polished) behavior may be an effect of (i) the rotation by $67^{\circ}$ of the scanning direction with every new applied layer and (ii) due to heat transfer and dissipation processes within the thermally conductive $\mathrm{CuCr} 1 \mathrm{Zr}$ alloy.

In Fig. 7, SEM micrographs of the etched microstructure (either polished and etched or electrolytically polished) of the $\mathrm{CuCr} 1 \mathrm{Zr}$ sample is shown. In the cross section shown in Fig. 7a, the melted scan tracks are visible showing that the $\mathrm{CuCr} 1 \mathrm{Zr}$ powder particles are completely fused together within melted and solidified zones having curved edges. The cross section also indicates that during LPBF a melt pool with a depth higher than the layer thickness is formed (approx. $100 \mu \mathrm{m}$ versus layer thickness of $20 \mu \mathrm{m}$ ). A fine cellular/dendritic structure is visible in Fig. $7 \mathrm{~b}$ where a higher magnification of the area highlighted in Fig. 7a was chosen. The formation of a cellular solidification structure oriented parallel and perpendicular to the image plane becomes obvious. This microstructure is formed as a result of rapid solidification due to very high cooling rates encountered in LPBF like in casting (see for example [20, 26]) and typical for laser processing techniques. Figure $7 \mathrm{c}$ shows the marked area of Fig. $7 \mathrm{~b}$ with higher magnification inside a cellular structure perpendicular to the building direction. Along borders of the cells, the formation of nanosized precipitates is occurring which were identified by EDX to be rich in $\mathrm{Zr}$ and $\mathrm{O}$ and are thus probably $\mathrm{ZrO}_{2}$.

Electric conductivity For all samples of the parameter study, the electric conductivity was measured by eddy current testing. The results are shown in Fig. 8 for all values of the parameter study with an error of $\pm 0.8 \mathrm{MS} / \mathrm{m}$. With increasing laser power, the electric conductivity increases accordingly which is in a reasonable agreement with the increasing relative density as shown in Fig. 4. For laser powers above 200 W, no pronounced dependency of the electric conductivity on the laser scanning velocity is detectable.

The reached maximum value of approx. 13.8 MS $/ \mathrm{m} \pm 0.8$ $\mathrm{MS} / \mathrm{m}$ is lower than the predetermined value of the German
Copper Institute, where values of $20 \mathrm{MS} / \mathrm{m}$ are stated for solution-annealed conditions [3]. The reason for the lower value might be the still remaining porosity of the LPBF-built samples. Furthermore, the homogeneously dissolved alloy components might impede the electric transport within the LPBF-built samples which was also reported for $\mathrm{Cu}-\mathrm{Cr}-\mathrm{Ni}$ Si alloys built by LPBF [2].

Surface roughness When evaluating the quality of an LPBF-built part, the surface roughness has to be considered besides the relative density and the microstructure. Due to the laser stop at the end of a hatching line and the adjacent powder particles within the powder bed that have not been included into the micro-welding process, unmelted powder particles might be attached to the part and lead to the formation of a rough surface. Furthermore, this effect is more pronounced with increasing mean diameter $d(0.5)$ because larger particles signify a higher topography variation than small particles. Furthermore, small particles might fill the gaps between the bigger ones, leading to a more stable micro-welding process.

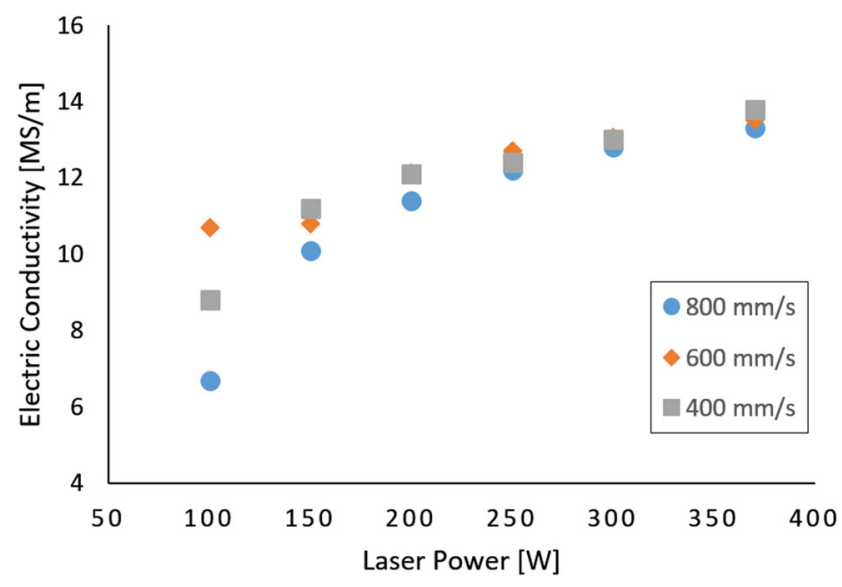

Fig. 8 Electric conductivity of $\mathrm{CuCr} 1 \mathrm{Zr}$ as measured within the parameter study 

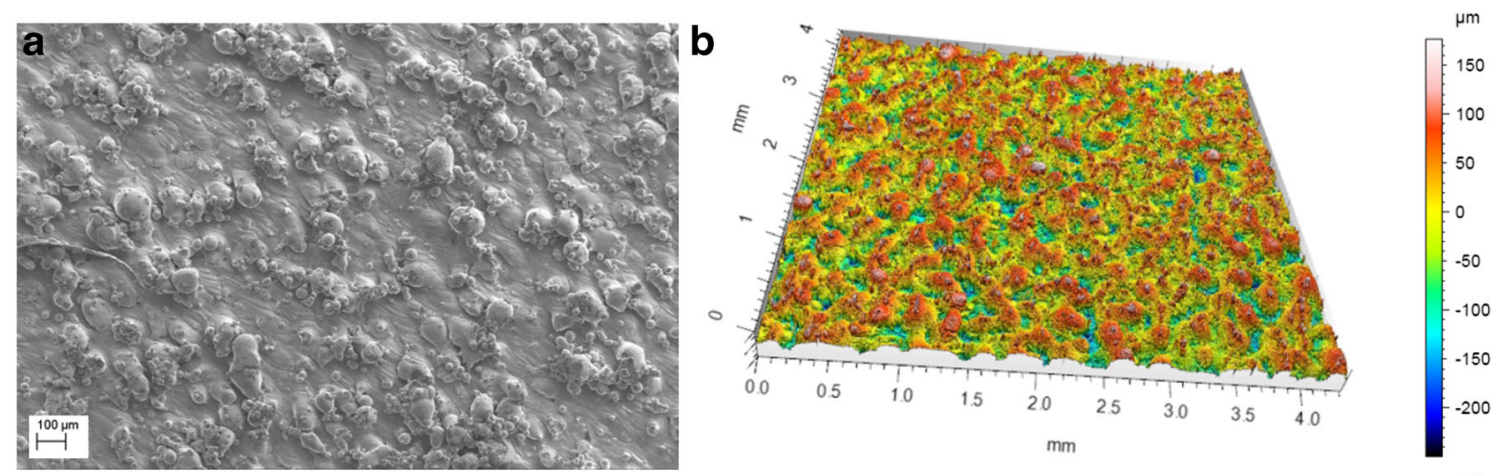

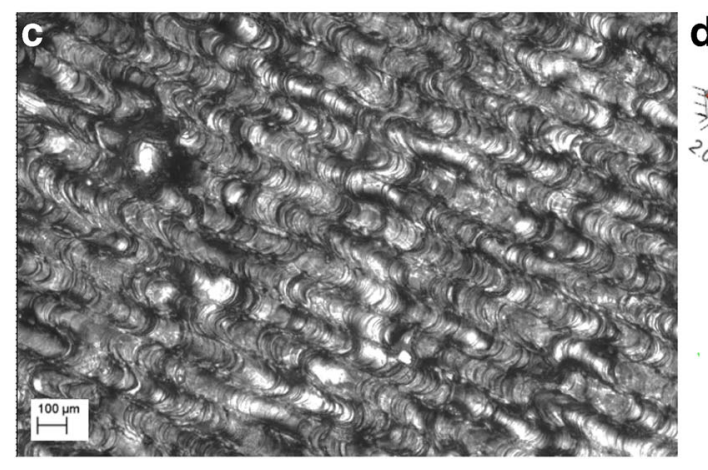

Fig. 9 Surface roughness of the upper surface of LPBF-built samples of CuCr1Zr. a SEM image of the surface showing unmelted powder particles. b Surface profile measurement with a confocal Nanofocus system revealing a depth profile of approx. $\pm 150 \mu \mathrm{m}$ resulting in a $R_{a}$ value of $40 \mu \mathrm{m} \pm 5 \mu \mathrm{m}$. c SEM micrograph of the surface after

Figure 9a shows an SEM image of an upper surface with unmelted powder particles. Obviously, powder particles with diameters higher than $50 \mu \mathrm{m}$ were only partially melted within the part and remain in spherical shape on the surface of the sample. In Fig. 9b, a surface profile measurement with a confocal Nanofocus reveals that the unmelted powder particles result in significant topography variations on the surface of LPBF-built samples. The resembling $R_{a}$ has a value of $40 \mu \mathrm{m} \pm 5 \mu \mathrm{m}$ which represents a high surface roughness. Furthermore, a laser power of $200 \mathrm{~W}$ and a laser scanning velocity of $800 \mathrm{~mm} / \mathrm{s}$ were used. An optimization might be achieved by (i) the application of optimized powders and (ii) implementation of a surface optimization routine. Hereby, the last layer of the sample is exposed manifold by the laser in order to completely melt the powder particles on top of the surface. Figure 9c and d show an SEM image and the corresponding topography profile, respectively, for a laser power of $200 \mathrm{~W}$ and $800 \mathrm{~mm} / \mathrm{s}$ laser scanning velocity, where four exposures were applied on the last layer. Compared to Fig. 9a and $\mathrm{b}$, the topography variations are significantly reduced, resulting in a $R_{a}$ value of $9 \mu \mathrm{m} \pm 2 \mu \mathrm{m}$. Further, the hatching lines of the laser are noticeable on the surface.
Altogether, the surface roughness is distinctly improved when a manifold exposure strategy was applied.

Figure 10a and $\mathrm{b}$ show the respective roughness qualities for all parameter sets of the parameter study for the upper and side surface of the cubic LPBF-built samples, repectively. It can be concluded that the $R_{a}$ value increases with increasing laser power, which means that the surface becomes rougher. The highest roughness was achieved for a laser power of $370 \mathrm{~W}$. In addition, the upper surfaces exhibit a lower roughness than the side surfaces which might be due to the multiple melting strategies that were performed on the top most powder layer as described earlier. It has to be mentioned that the error for the distinct measurements shown in Fig. 10 varies between $\pm 2-4 \mu \mathrm{m}$. Especially for the investigated areas on the side surfaces, the influence of locally unmelted powder particles leads to a higher deviation and thus a lower accuracy of the experimental results.

Thus, the parameters that lead to samples with the best relative optical densities as discussed beforehand also result in the formation of the roughest surface. In this case, the effect of the roughness on material properties for applications, where the surface quality plays a significant role, like the high-temperature heat exchangers, have to be 

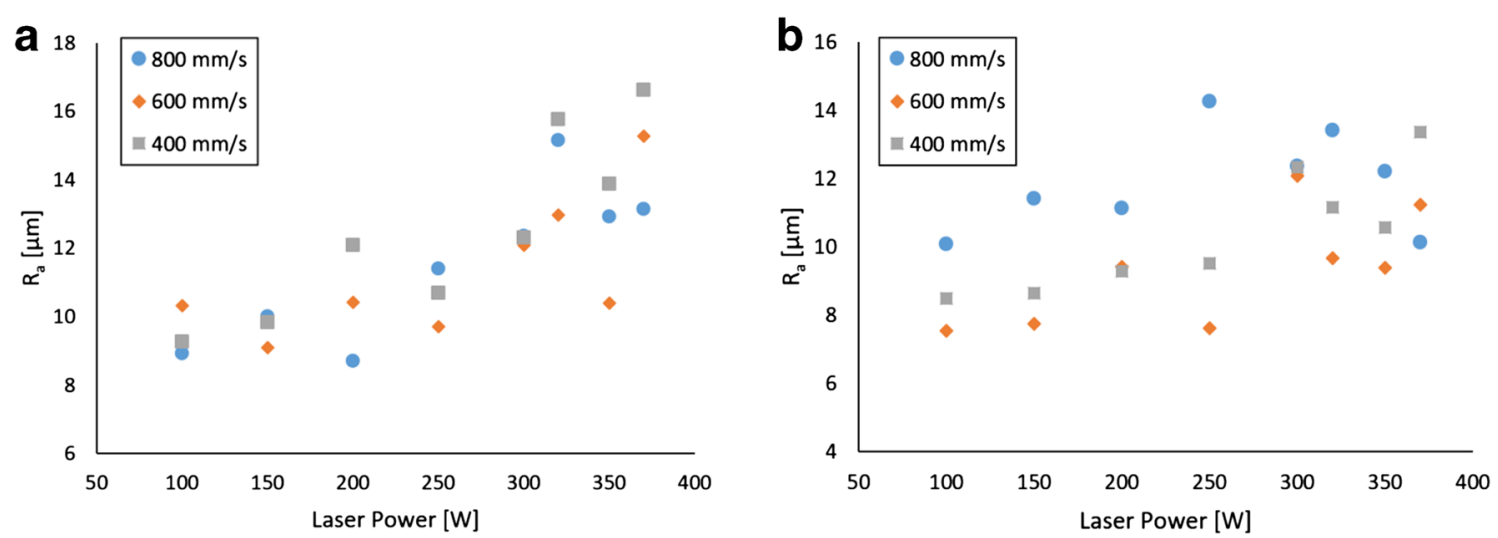

Fig. 10 Surface roughness of LPBF-built $\mathrm{CuCr} 1 \mathrm{Zr}$ as measured within the parameter study: a side surfaces, $\mathbf{b}$ upper surface

analyzed. Furthermore, the application of surface treatments like polishing or peening is possible.

\subsection{Heat treatment on LPBF-built CuCr1Zr samples}

By application of heat treatments, a precipitation hardening of $\mathrm{Cu}$ alloys may be achieved. In the case of $\mathrm{CuCr} 1 \mathrm{Zr}$, the formation of $\mathrm{Cr}, \mathrm{Cu}_{4} \mathrm{Zr}$, and $\mathrm{Cr}_{2} \mathrm{Zr}$ precipitates lead to an increase (i) in hardness and (ii) of the electric conductivity [2-5, 32]. Ageing was performed at $480^{\circ} \mathrm{C}$ for $4 \mathrm{~h}$.

LPBF specimens built with a laser power of $370 \mathrm{~W}$ and laser scanning velocity of 400,600, and $800 \mathrm{~mm} / \mathrm{s}$ were used. Furthermore, ageing, hardness, and electric conductivity measurements were also performed on a cast benchmark sample as described earlier. The results are shown in Fig. 11a. Before ageing, the LPBF-built sample exhibits a hardness of $92 \mathrm{HV} 0.1 \pm 2 \mathrm{HV} 0.1$ and the cast sample of $65 \mathrm{HV} 0.1 \pm 4 \mathrm{HV} 0.1$. The increased hardness of the LPBF sample might be explained by the small precipitates shown in Fig. 7 that are occurring at the grain boundaries and probably have a pinning effect on the subgrain structure. After ageing, the hardness was increased to values exceeding $200 \mathrm{HV} 0.1 \pm 1 \mathrm{HV} 0.1$ for the LPBFbuilt and to $131 \mathrm{HV} 0.1 \pm 3 \mathrm{HV} 0.1$ for the cast sample.

Investigations on the electric conductivity shown in Fig. $11 \mathrm{~b}$ exhibit values that are comparable with conventionally built samples after ageing. Thus, although the electric conductivity was comparably low before heat treatment, the performance of a post-LPBF ageing process leads to an adjustment of the electric conductivity that equals or slightly exceeds the value of the benchmark sample.

Figure 12 shows the microstructure of a LPBF-built sample ( $370 \mathrm{~W}$ and $400 \mathrm{~mm} / \mathrm{s}$ ) obtained by SEM and TEM, respectively. Compared to the microstructure before ageing as shown in Fig. 7, the microdendritic subgrain structure seems to be dissolved with a concomitant precipitation of
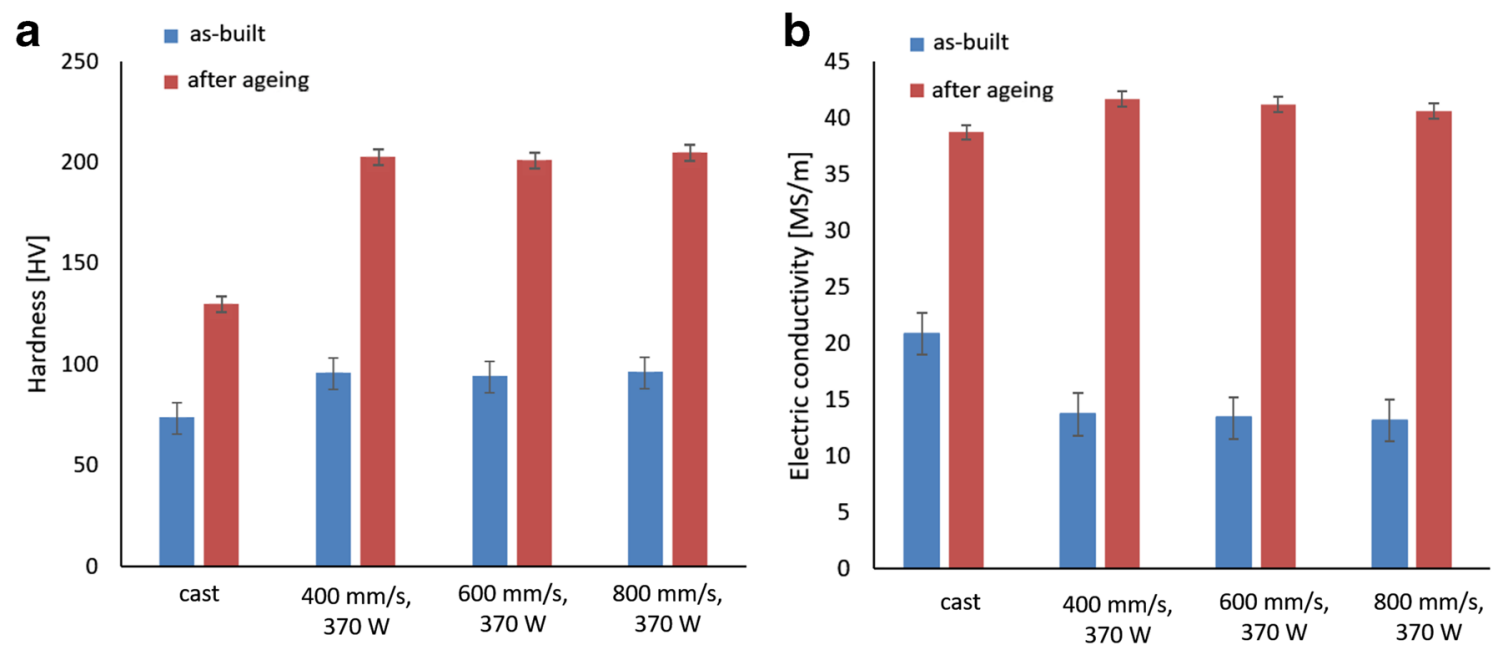

Fig. 11 a Vickers hardness HV0.1 of the benchmark (cast) and LPBF-built samples. b Electric conductivity of the benchmark (cast) and LPBF-built samples 

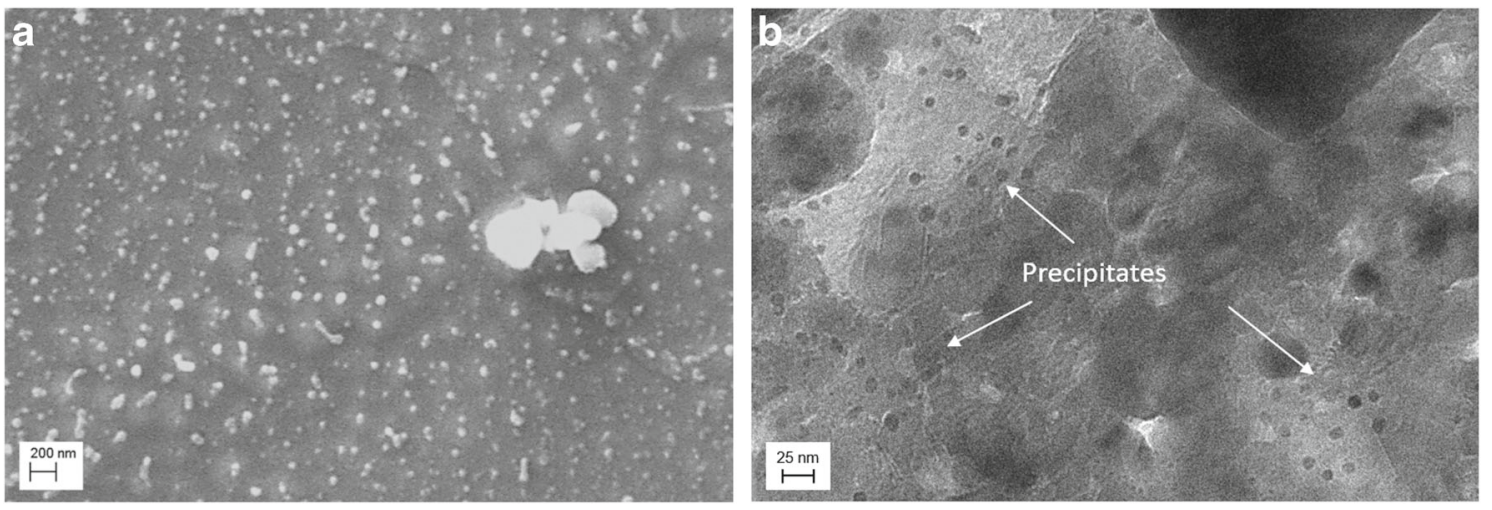

Fig. 12 Precipitation-hardened $\mathrm{CuCr} 1 \mathrm{Zr}$ samples manufactured by LPBF. a SEM image showing small dispersal distributed $\mathrm{ZrO}_{2}$ precipitates. b TEM image showing nano-sized precipitates

probable $\mathrm{ZrO}_{2}$ either as nanometer-sized precipitates all over the sample or as micrometer-sized agglomerations of $\mathrm{ZrO}_{2}$ at grain boundaries (see Fig. 12a). For non LPBFbuilt samples, the formation of $\mathrm{ZrO}_{2}$ as a strengthening phase is neither reported for non-aged nor for aged samples. However, they tend to have a strengthening effect in LPBF-built $\mathrm{CuCr} 1 \mathrm{Zr}$ by their fine dispersion, leading to a significantly higher hardness as compared to the benchmark sample and to literature values (for example to [2, 3, 32]). The TEM image of Fig. 12b reveals the occurrence of nano-sized precipitates, probably being rich in $\mathrm{Cr}$, which were also reported in [32] that have a strengthening effect in $\mathrm{CuCr} 1 \mathrm{Zr}$. Thus, the formation of probably $\mathrm{Cr}$ rich precipitates on the nano-scale and $\mathrm{ZrO}_{2}$ an the microscale after ageing lead to a significant increase in hardness, exceeding the values of the cast benchmark samples and values reported in, e.g., [2, 32].

\section{Conclusion and summary}

In this work, a process routine for additive manufacturing of $\mathrm{CuCr} 1 \mathrm{Zr}$ was developed and the material properties of the additively manufactured samples regarding density, hardness, conductivity, and surface roughness were related to the applied process parameters. The focus was set on (i) the generation of metallic powders of $\mathrm{CuCr} 1 \mathrm{Zr}$ by gas atomization for additive manufacturing processes, (ii) LPBF of the previously produced $\mathrm{CuCr} 1 \mathrm{Zr}$ powders, and (iii) the investigation of functional properties and heat treatment on the LPBF-built $\mathrm{CuCr} 1 \mathrm{Zr}$ compared to conventionally manufactured benchmark samples. Altogether, process parameters were identified by which the generation of dense samples with material properties comparable to those conventionally cast materials was successful.

Regarding the generation of $\mathrm{CuCr} 1 \mathrm{Zr}$ powders by gas atomization, the close-coupled mode was used in order to produce powders with diameters below $100 \mu \mathrm{m}$ that is generally suitable for LPBF. By air separation and sieving, the particles with diameters below $10 \mu \mathrm{m}$ and greater than $70 \mu \mathrm{m}$ were removed, respectively. The particles reveal to have a spherical shape and only modest satellite formation. At the grain boundaries, the occurrence of occasionally distributed $\mathrm{ZrO}_{2}$ is visible.

By performance of a parameter study, process parameters for LPBF were identified that result in the additive manufacturing of dense samples. For industrial applications of $\mathrm{CuCr} 1 \mathrm{Zr}$, the density as well as the hardness and the electric conductivity is of importance. Thus, these values were investigated for all parameter sets of the parameter study. It can be concluded that a laser power higher than $300 \mathrm{~W}$ has to be used in order to manufacture samples with densities exceeding 99.7\%. However, the surface becomes rougher with increasing laser power which has to be considered when considering industrial applications where the surface constitution is not neglectable. A post-LBPF heat treatment leads to a significant increase in hardness exceeding the values of conventionally manufactured benchmark samples which is due to the formation of $\mathrm{Cr}$ precipitates on the nano-scale and $\mathrm{ZrO}_{2}$ an the micro-scale

Altogether, the application of self-produced $\mathrm{CuCr} 1 \mathrm{Zr}$ powders for LPBF results in manufactured parts with reasonable functional properties for industrial applications with a comparably high hardness and electrical conductivity after a post-LPBF heat treatment.

Acknowledgments Open Access funding provided by Projekt DEAL.

Funding information This study received financial support from EFRE (European Fond for Regional Development).

Open Access This article is licensed under a Creative Commons Attribution 4.0 International License, which permits use, sharing, adaptation, distribution and reproduction in any medium or format, as long as you give appropriate credit to the original author(s) and the source, provide a link to the Creative Commons licence, and indicate 
if changes were made. The images or other third party material in this article are included in the article's Creative Commons licence, unless indicated otherwise in a credit line to the material. If material is not included in the article's Creative Commons licence and your intended use is not permitted by statutory regulation or exceeds the permitted use, you will need to obtain permission directly from the copyright holder. To view a copy of this licence, visit http://creativecommons. org/licenses/by/4.0/.

\section{References}

1. Kuhn HA, Käufler A, Hölzl H, Altenberger I, Fünfer M (2012) Properties of high performance alloys for electromechanical connectors. In: Copper alloys-early applications and current performance-enhancing processes. INTECH Open Access Publisher, pp 51-68

2. Becker D (2014) Selektives Laserschmelzen von Kupfer und Kupferlegierungen, Edition Wissenschaft Apprimus, 1st edn. Apprimus, Aachen

3. Deutsches Kupferinstitut (2018) Niedriglegierte Kupferwerkstoffe, available online at www.kupferinstitut.de

4. Edwards DJ, Singh BN, Tähtinen S (2007) Effect of heat treatments on precipitate microstructure and mechanical properties of a CuCrZr alloy. J Nucl Mater 367:904-909

5. Durashevich G, Cvetkovski V, Jovanovich V (2002) Effect of thermomechanical treatment on mechanical properties and electrical conductivity of a CuCrZr alloy. Bull Mater Sci 25.1:59-62

6. Thompson SM, Bian L, Shamsaei N, Yadollahi A (2015) An overview of direct laser deposition for additive manufacturing; part i: transport phenomena, modeling and diagnostics. Additive Manuf 8:36-62

7. Zhang K, Liu W, Shang X (2007) Research on the processing experiments of laser metal deposition shaping. Opt Laser Technol 39(3):549-557

8. Weng F, Gao S, Jiang J, Wang J, Guo P (2019) A novel strategy to fabricate thin $316 \mathrm{~L}$ stainless steel rods by continuous directed energy deposition in $\mathrm{Z}$ direction. Additive Manufac 27:474-481

9. Graf B, Gumenyuk A, Rethmeier M (2012) Laser metal deposition as repair technology for stainless steel and titanium alloys. Phys Procedia 39:376-381

10. Kattire P, Paul S, Singh R, Yan W (2015) Experimental characterization of laser cladding of CPM $9 \mathrm{~V}$ on $\mathrm{H} 13$ tool steel for die repair applications. J Manuf Process 20(3):492-499

11. Hofmann DC, Roberts S, Otis R, Kolodziejska J, Dillon RP, Suh J-O, Shapiro AA, Liu Z-K, Borgonia J-P (2014) Developing gradient metal alloys through radial deposition additive manufacturing. Sci Rep 4:5357

12. Lai Q, Abrahams R, Yan W, Qiu C, Mutton P, Paradowska A, Soodi M (2017) Investigation of a novel functionally graded material for the repair of premium hypereutectoid rails using laser cladding technology. Compos Part B: Eng 130:174-191

13. Khairallah SA, Anderson AT, Rubenchik A (2016) Laser powderbed fusion additive manufacturing. Acta Materialia 108:36-45

14. Ning J, Sievers DE, Garmestani H, Liang SY (2019) Analytical modeling of in-process temperature in powder bed additive manufacturing considering laser power absorption, latent heat, scanning strategy, and powder packing. Materials 12(5):808

15. Gong H, Rafi K, Gu H, Starr T, Stucker B (2014) Analysis of defect generation in Ti-6Al-4V parts made using powder bed fusion additive manufacturing processes. Additive Manuf 1:8798

16. Heigel JC, Michaleris P, Palmer TA (2015) In situ monitoring and characterization of distortion during laser cladding of Inconel ${ }^{\circledR}$ 625. J Mater Process Technol 200:135-145

17. Zhao C, Fezzaa K, Cunningham RW (2017) Real-time monitoring of laser powder bed fusion process using high-speed X-ray imaging and diffraction. Sci Rep 7:3602

18. Manvatkar V, De A, DebRoy T (2014) Heat transfer and material flow during laser assisted multi-layer additive manufacturing. J Appl Phys 116:124905

19. Gu DD, Meiners W, Wissenbach K (2012) Laser additive manufacturing of metallic components: materials, processes and mechanisms. Int Mater Rev 57:133-164

20. Köhnen P, Létang M, Voshage M, Schleifenbaum JH, Haase C (2019) Understanding the process-microstructure correlations for tailoring the mechanical properties of L-PBF produced austenitic advanced high strength steel. Additive Manuf 30:100914

21. Ning J, Sievers DE, Garmestani H, Liang SY (2019) Analytical thermal modeling of metal additive manufacturing by heat sink solution. Materials 12(16):2568

22. Meier H, Haberland C (2008) Experimental studies on selective laser melting of metallic parts. Materialwissenschaft und Werkstofftechtechnik 39.9:665-670

23. Schwenck D, Ellendt N, Mädler L., Fischer-Bühner J, Hofmann P, Uhlenwinkel V (2014) Generation of small batch high quality metal powder. Powder Metall 57(3):171-175

24. Schwenck D, Ellendt N, Fischer-Bühner J, Hofmann P, Uhlenwinkel V (2017) A novel convergent-divergent annular nozzle design for close-coupled atomisation. Powder Metall 60(3):198207

25. Seyda V (2018) Werkstoff-und Prozessverhalten von Metallpulvern in der laseradditiven Fertigung. Springer-Verlag

26. Rombouts M (2006) Selective laser sintering/melting of ironbased powders, $\mathrm{PhD}$ thesis, Catholic University of Leuven. Heverlee

27. El-Wardany TI, She Y, Jagdale VN, Garofano JK, Liou JJ, Schmidt WR (2018) Challenges in three-dimensional printing of high-conductivity copper. J Electron Packag 140(2):020907

28. Popovich A, Sufiiarov V, Polozov I, Borisov E, Masaylo D, Orlov A (2016) Microstructure and mechanical properties of additive manufactured copper alloy. Mater Lett 179:38-41

29. Zhang S, Zhu H, Zhang L, Zhang W, Yang H, Zeng $X$ (2019) Microstructure and properties of high strength and high conductivity $\mathrm{Cu}-\mathrm{Cr}$ alloy components fabricated by high power selective laser melting. Mater Lett 237:306-309

30. Chen Y, Ren S, Zhao Y, Qu X (2019) Microstructure and properties of $\mathrm{CuCr}$ alloy manufactured by selective laser melting. Journal of Alloys and Compounds. https://doi.org/10.1016/j.jallcom. 2019.01.179

31. Palousek D, Kocica M, Pantelejev L, Klakurkova L, Celko L, Koutny D, Kaiser J (2019) SLM process parameters development of Cu-alloy Cu7.2Ni1.8Si1C. Rapid Prototyp J 25(2):266276

32. Kováčová A, Kvačkaj T, Kočiško R, Dragošek L, LityńskaDobrzyńska L (2017) The effect of severe plastic deformation and heat treatment on $\mathrm{CuCrZr}$ alloys. Acta Physica Polonica A 131(5):1336-1339

Publisher's note Springer Nature remains neutral with regard to jurisdictional claims in published maps and institutional affiliations. 